\title{
An uncommon cause of chronic upper GI bleeding
}

\author{
Paul Korc, MD \\ Hoag-USC Digestive Disease Center, Newport Beach, California, USA \\ Lee McHenry, MD \\ Indiana University, Indianapolis, Ind, USA
}

A 68-year-old woman presented with 4 years of iron deficiency anemia, requiring intravenous iron infusion. EGD revealed a 10-mm, cherry-red, sessile polypoid lesion on the major duodenal papilla. EUS examination was negative for deep invasion. Endoscopic ampullectomy was performed. A residual focus of lesion was treated with argon plasma coagulation (APC) after placement of a protective pancreatic duct stent (Video 1, available online at www.giejournal.org). Pathologic examination revealed a proliferation of capillaries with acute and chronic inflammation, consistent with pyogenic granuloma. Figure 1 demonstrates the lesion's appearance (Fig. 1A) and the histology at $\times 100$ magnification (Fig. 1B). Pyogenic granuloma is a lobular capillary hemangioma that presents as a polypoid red mass. Most often, they occur on the skin or oral mucosa but can, rarely, be found in the GI tract. Pyogenic granuloma of the duodenum is particularly rare. To our knowledge, only 2 cases of pyogenic granuloma (capillary hemangioma) with major papilla involvement have been reported, both in the Spanish language literature (de Caralt, 1986; Camacho, 2012). Pyogenic granuloma should be considered in the differential diagnosis of chronic GI bleeding. If the major papilla is involved, ampullectomy followed by APC for any residual lesion appears to be a safe and effective treatment.

\section{Disclosure}

All authors disclosed no financial relationships relevant to this publication.

Supplementary data: Video available from the publisher's website.

This is the author's manuscript of the article published in final edited form as:

Korc, P., \& McHenry, L. (2016). An uncommon cause of chronic upper GI bleeding. Gastrointestinal Endoscopy, 84(3), 524. https://doi.org/10.1016/j.gie.2016.03.1483 
Figure 1. A, Endoscopic finding: lesion at major duodenal papilla. B, Histology (H\&E, orig. mag. × 100) showing a proliferation of capillaries with acute and chronic inflammation.
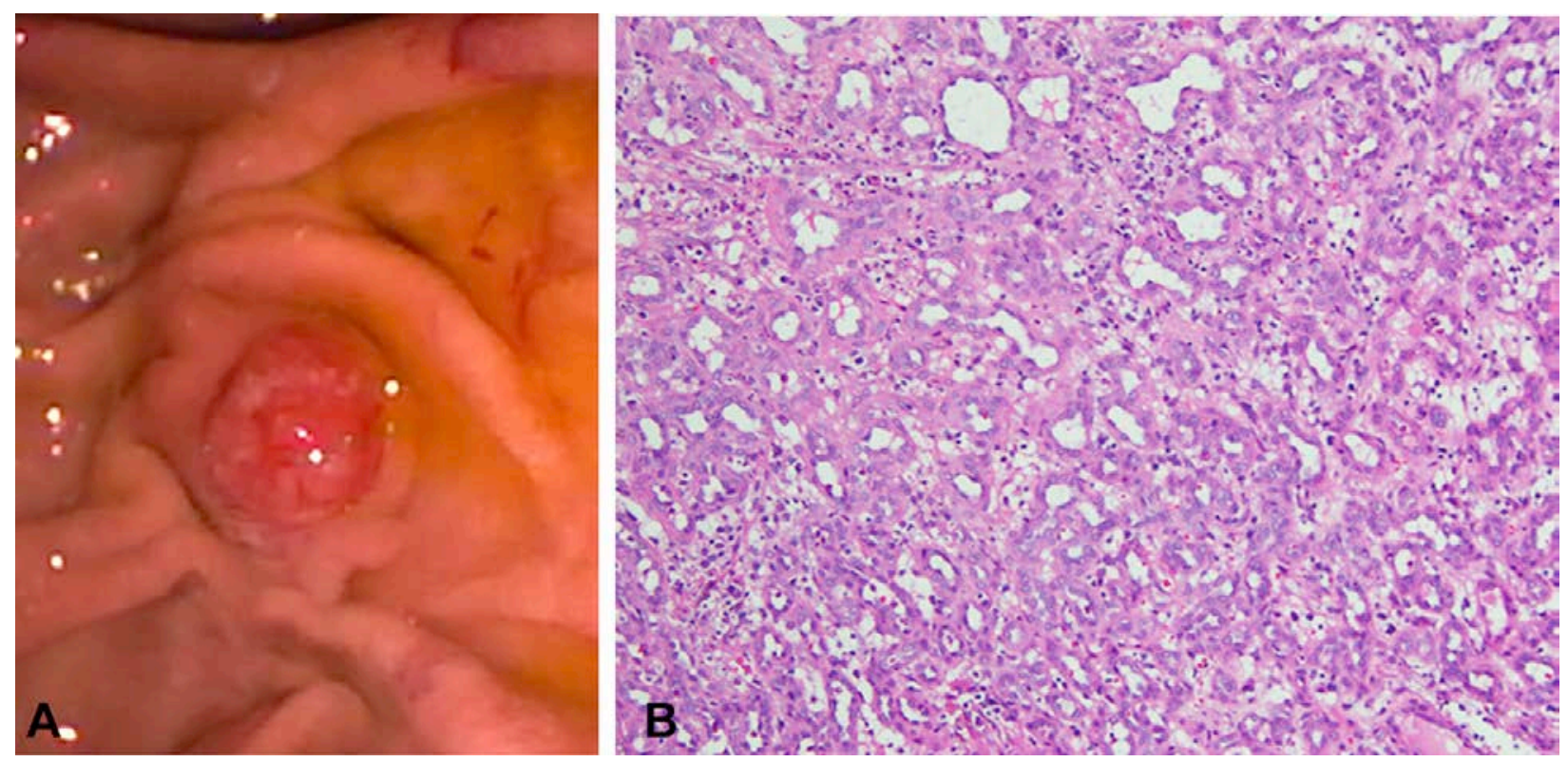